\title{
The influence of an applied standard test method on a measurement of concrete stabilized secant modulus of elasticity
}

\author{
Lucyna Domagała ${ }^{1, *}$, and Justyna Dobrowolska ${ }^{1}$ \\ ${ }^{1}$ Cracow University of Technology, ul. Warszawska 24, Cracow 31-155, Poland
}

\begin{abstract}
The paper focuses on the influence of the standard test method applied to determine the concrete stabilized secant modulus on a specified value. The new European Standard EN 12390-13 for testing hardened concrete accepts two methods (A and B) for the determination of the secant modulus of elasticity in compression. The aim of the research was to establish how different testing procedures affect a measured value of modulus of elasticity. Four structural concrete series: two lightweight aggregate concretes and two normal-weight ones were subject to tests of moduli of elasticity determined by both standard methods, as well as compressive strength and density. The carried out tests revealed that the procedure of testing modulus of elasticity influenced a measured value. Method A led to higher values of modulus in relation to Method B, irrespective of concrete density and strength. Nevertheless, a certain relationship between the concrete structure homogeneity and the difference in results of moduli determined by both methods may be observed.
\end{abstract}

\section{Introduction}

Modulus of elasticity is one of the most important mechanical properties of concrete which has a significant impact on the structural design process. There are many types of concrete moduli of elasticity (dynamic, static initial tangent, tangent, stabilized secant, initial secant), however it is the stabilized secant one which is fundamentally taken into consideration at structural member designing. Until recently, in many European countries various guidelines for this modulus determination were in force. These documents differed in testing procedures, especially in terms of the moisture condition of specimens to be tested, the lower and the upper stress values and a number of loading and unloading cycles. As a result, the values of modulus determined by different testing methods may have varied more than those specified by one method for concretes of different strength classes [1-9].

Fortunately, in 2013, a new European Standard, EN 12390-13 [10], dedicated for the determination of the secant modulus of elasticity in compression, was published at last. This long awaited standard on one hand unifies to some extent the procedures of modulus testing, on the other hand it leaves a certain freedom in selection of the specimen type and number, as well as the testing method.

\footnotetext{
*Corresponding author: ldomagala@pk.edu.pl
} 


\section{Standard test methods for determination of the secant modulus of elasticity}

The new standard EN 12390-13 [9] accepts two methods of determination of concrete modulus of elasticity: Method A and Method B. Method A is more complex and requires longer time for testing, but it allows the determination of two secant moduli of elasticity: the initial secant modulus $\left(E_{C, 0}\right)$ and the stabilized secant modulus $\left(E_{C, S}\right)$. It should be noticed that it is the stabilized modulus which value is used in the structure designing process. However, the degree of variation of these two moduli may be helpful for assessment of the material susceptibility to stress induced micro-cracking or micro-cracking caused by drilling in the case of cores taken from a structure. The second method (Method B), intended only for the determination of the stabilized secant modulus, is much simpler, requires shorter time and as a result it is much more often applied by researchers.

Nevertheless, there is no information neither in the standard nor in the scientific literature on the difference in the modulus values determined by these two standard methods.

\subsection{Method A}

The testing procedure according to Method A consists of three initial preloading cycles in the stress range from $\sigma_{p}=0.5 \mathrm{MPa} \div \sigma_{b}$ up to $\sigma_{b}=0.10 \div 0.15 \cdot f_{c m}$ (where $f_{c m}$ - mean compressive strength) and three main loading cycles in the stress range from the lower stress $\sigma_{b}$ up to the upper stress $\sigma_{a}=f_{c m} / 3$ (Fig. 1). The initial secant modulus is determined at the first main loading cycle, while the stabilized secant modulus is measured at the last, the third cycle. Finaly the stabilized secant modulus is calculated according to formula (1), where $\sigma_{a}{ }^{m}$ and $\sigma_{b}{ }^{m}$ are the stress values measured at the third cycle while $\varepsilon_{a, 3}$ and $\varepsilon_{b, 2}$ are the corresponding strains.

$$
E_{C, S}=\frac{\sigma_{a}^{m}-\sigma_{b}^{m}}{\varepsilon_{a, 3}-\varepsilon_{b, 2}}
$$

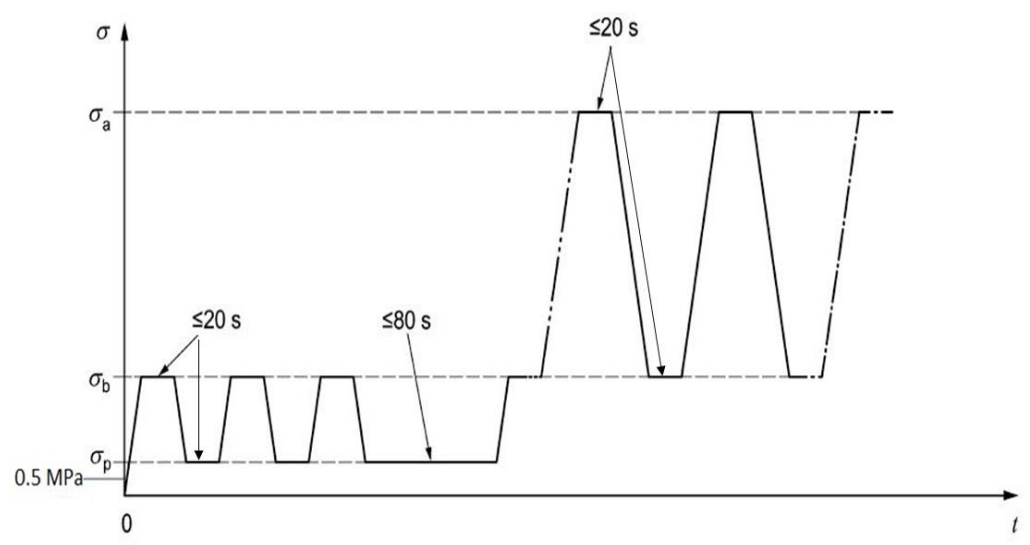

Fig.1. Cycle for the determination of initial and stabilized modulus of elasticity according to Method A. 


\subsection{Method B}

The testing procedure according to Method B consists only of three main loading cycles in the stress range from the lower stress $\sigma_{p}$ up to the upper stress $\sigma_{a}$. (Fig. 2). The values of $\sigma_{p}$ and $\sigma_{a}$ are assumed as for Method A. As a result, the stabilized secant modulus is calculated according to formula (2), where $\sigma_{a}{ }^{m}$ and $\sigma_{b}{ }^{m}$ are the stress values measured at the third cycle while $\varepsilon_{a, 3}$ and $\varepsilon_{p, 2}$ are the corresponding strains.

$$
E_{c, s}=\frac{\sigma_{a}^{m}-\sigma_{p}^{m}}{\varepsilon_{a, 3}-\varepsilon_{p, 2}}
$$

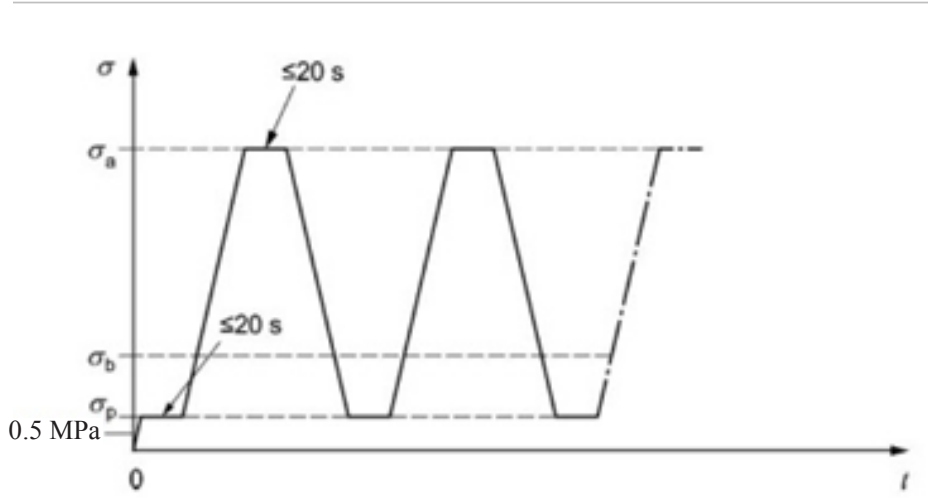

Fig.2. Cycle for the determination of stabilized secant modulus of elasticity according to Method B.

\section{Experimental details}

The research aim was to check whether both standard methods for determination of modulus of elasticity (Method A and Method B) lead to the same test result. In the case of different measurements, the scope was to analyse whether the difference of moduli specified by these two methods is dependent on the concrete strength and type.

\subsection{Materials}

Four series of structural concretes of different strength and density classes were subject to tests. All series were made of Portland cement CEM I 42.5 R, natural sand as fine aggregate and tap water. Two types of coarse aggregate were used: natural sandstone gravel $4 / 16 \mathrm{~mm}$ as normal-weight aggregate and sintered fly ash $4 / 8 \mathrm{~mm}$ as lightweight one. Sintered fly ash was initially wetted to the moisture content of $17 \%$ by mass to eliminate the risk of workability loss. Two water - cement ratios were taken into consideration: 0.37 and 0.55 . The constant volume proportion of cement mortar to coarse aggregate (55\%:45\%) was assumed for all concrete series. In the case of $w / c=0.37$ additionally superplasticizer was applied to ensure workability similar to concrete mixtures of $w / c=0.55$. The composition of all prepared mixtures are presented in Table 1.

6 standard cylinders $(150 / 300 \mathrm{~mm})$ and 6 standard cubes $(150 \mathrm{~mm})$ were moulded from each series of concrete mixtures. 
Table 1. Composition of normal-weight concretes (NC) and lightweight concretes (LC).

\begin{tabular}{|c|c|c|c|c|c|c|c|}
\hline \multirow[b]{2}{*}{ Series } & \multirow[b]{2}{*}{$\mathbf{w} / \mathbf{c}$} & \multicolumn{6}{|c|}{ Constitiuent Materials $\left[\mathrm{kg} / \mathrm{m}^{3}\right]$} \\
\hline & & $\begin{array}{c}\text { Coarse } \\
\text { aggregate }\end{array}$ & $\begin{array}{c}\text { Water for } \\
\text { initial wetting } \\
\text { of coarse agg. }\end{array}$ & $\begin{array}{c}\text { Natural } \\
\text { sand }\end{array}$ & $\begin{array}{c}\text { Cement } \\
\text { (c) }\end{array}$ & $\begin{array}{c}\text { Water } \\
\text { (w) }\end{array}$ & $\begin{array}{c}\text { Super- } \\
\text { plasticizor }\end{array}$ \\
\hline $\mathrm{NC} 1$ & 0.55 & 1140 & 0 & 570 & 377 & 208 & 0 \\
\hline $\mathrm{NC} 2$ & 0.37 & 1140 & 0 & 570 & 470 & 174 & 1.88 \\
\hline LC1 & 0.55 & 576 & 98 & 570 & 377 & 208 & 0 \\
\hline $\mathrm{LC} 2$ & 0.37 & 576 & 98 & 570 & 470 & 174 & 1.88 \\
\hline
\end{tabular}

\subsection{Testing methods}

All tests were carried out on specimens cured for 28 days in water in standard conditions according to EN 12390-2 [10]. At the beginning for each concrete series 3 cylindrical specimens were tested according to EN 12390-3 [11] to determine the mean value of compressive strength $\left(f_{c m, c y l}\right)$. The rest 3 cylindrical specimens of each concrete series were applied for determination of modulus of elasticity according to Method A and B of EN 12390-13 [8]. In both methods the stress of $0.5 \mathrm{MPa}$ was assumed as $\sigma_{p}$ and the value of $1 / 3$ $f_{c m, c y l}$ was taken as the upper stress $\sigma_{a}$. However, in the case of Method A the value of $0.1 f_{c m, c y l}$ was taken as the lower stress $\sigma_{b}$, while for Method B the lower stress was assumed as $\sigma_{p}$. The testing equipment applied for determination of modulus of elasticity consisted of a programmable compression testing machine and a strain meassuring set of 3 extensometers (Fig. 3 ).

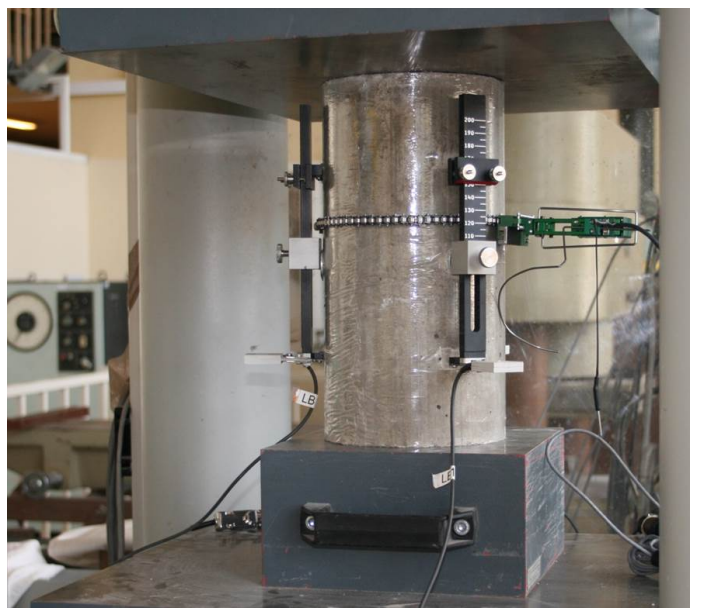

Fig. 3. A concrete specimen with the measuring equipment for modulus determination.

In order to eliminate the influence of material heterogeneity of a specimen, the arrengment of a specimen in relation to machine platens and the location of strain sensors in relation to a specimen on a measurement of modulus of elasticity, tests according to procedures A and B were carried out in sequence on each specimen. According to well-known rules, repeated or cyclic loading of concrete up to the stress as low as $1 / 3 f_{\mathrm{cm}}$, which is considerable lower than the fatique strength, should not affect the measurement of modulus of elasticity $[1,2,12]$. Nevertheless, just in case, the measurement repeatability was checked prior to main tests of modulus of elasticity. Therefore selected specimens, ultimately predicted for initial compressive strength determination, 
were subject to earlier tests of modulus in sequince according to following methods order: A-BA-B-A or B-A-B-A-B. Before each next test a specimen was completely unloaded, however its position in relation to the compressive testing machine platens was reteined.

Moreover, saturated and oven-dry densities were tested on cube specimens, according to EN 12390-7 [13]. The results of density tests made it possible to assess the moisture content of specimens during modulus testing.

\section{Results and discussion}

Application of various type of coarse aggregate and cement matrix resulted in different properties of all four hardened concretes. Their compressive strength ranged from $33.5 \mathrm{MPa}$ up to $59.3 \mathrm{MPa}$, while corresponding oven-dry density varied from $1690 \mathrm{~kg} / \mathrm{m}^{3}$ up to 2290 $\mathrm{kg} / \mathrm{m}^{3}$. The test results of compressive strength, oven-dry and saturated density, as well as moisture content are given in Table 2.

Table 2. Basic properties of normal-weight concretes (NC) and lightweight concretes (LC).

\begin{tabular}{|c|c|c|c|c|c|}
\hline Series & $\begin{array}{c}\text { Mean } \\
\text { compressive } \\
\text { strength }\left(\mathbf{f}_{\mathrm{cm}, \mathrm{cyl}}\right) \\
{[\mathrm{MPa}]} \\
\end{array}$ & $\begin{array}{c}\text { Standard } \\
\text { deviation of } \\
\text { strength } \\
{[\mathrm{MPa}]} \\
\end{array}$ & $\begin{array}{c}\text { Mean } \\
\text { saturated } \\
\text { density } \\
{\left[\mathrm{kg} / \mathrm{m}^{3}\right]}\end{array}$ & 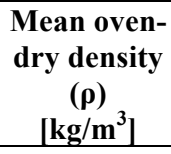 & $\begin{array}{c}\text { Mean } \\
\text { moisture } \\
\text { content } \\
{[\%]} \\
\end{array}$ \\
\hline NC1 & 42.9 & 1.5 & 2310 & 2220 & 4.1 \\
\hline $\mathrm{NC2}$ & 59.5 & 1.0 & 2340 & 2290 & 2.2 \\
\hline LC1 & 33.5 & 0.6 & 1840 & 1690 & 8.9 \\
\hline LC2 & 45.3 & 1.6 & 1890 & 1780 & 6.2 \\
\hline
\end{tabular}

Repeatability tests of modulus of elasticity, carried out for several specimens randomly selected from normal-weight and lightweight concretes, proved that there is no visible difference in results determined on the same specimen according to one method (A or B). Results of moduli tested in sequence several times by the same method revealed usually no changes or varied at the most by $0.3 \mathrm{GPa}$. This value is much lower than the difference of results usually achieved for various specimens of the same concrete. All values of moduli measured according to methods $\mathrm{A}$ and $\mathrm{B}$ on the same specimen, regardless of the type of concrete, varied visibly. Nevertheless, it should be stated that the order of applied methods (method A after or before B) did not reflect the measurement of the stabilized secant modulus $\left(E_{C, S}\right)$ obtained in the same testing procedure. However, in any sequent test a higher value of the initial secant modulus $\left(E_{C, 0}\right)$ was reached in comparison to the first test. It was caused by a certain durable compression of concrete structure during the previous loading. Consequently a specimen behaved as stiffer at the first loading cycle of next tests. Therefore, in order not to disturb the measurement of $E_{C, 0}$, in the main tests all specimens were firstly subject to Method A and then to Method B. The relationship between initial and stabilized moduli, with respect of the types of concrete considered hereby, are discussed in [14].

The obtained test results of the stabilized secant moduli of elasticity determined according to both standard methods as well as their interrelationships are presented in Table 3 .

Generally, application of less stiff lightweight aggregate instead of normal-weight one caused the reduction of modulus of elasticity by $30 \%$ on average. This decrease was slightly more pronounced for the concrete made of weaker cement matrix strength $(\mathrm{w} / \mathrm{c}=0.55)$. However, in the case of the same coarse aggregate type the application of the weaker mortar resulted in moduli lower by ca $18 \%$ in relation to concretes prepared with stronger matrix 
$(\mathrm{w} / \mathrm{c}=0.37)$. The decrease resulting from the weaker matrix application was insensibly higher for lightweight concrete.

Table 3. Stabilized secant moduli of elasticity determined according to Methods A and B for normalweight concretes (NC) and lightweight concretes (LC) and their relationships.

\begin{tabular}{|c|c|c|c|c|c|c|c|c|c|c|}
\hline \multirow[b]{2}{*}{ Series } & \multicolumn{3}{|c|}{ Method A } & \multicolumn{3}{|c|}{ Method B } & \multirow{2}{*}{$\begin{array}{c}\mathbf{E}_{\mathbf{C}, \mathbf{S A}} / \\
\mathbf{E}_{\mathbf{C}, \mathbf{B}} \\
{[\%]}\end{array}$} & \multirow{2}{*}{$\begin{array}{c}\mathbf{E}_{\mathbf{C}, \mathbf{S A m}} / \\
\mathbf{E}_{\mathbf{C , S B m}} \\
{[\% \mathbf{\%}]}\end{array}$} & \multirow{2}{*}{$\begin{array}{c}\mathbf{E}_{\mathbf{C}, \mathbf{S A}} \\
\mathbf{E}_{\mathbf{C}, \mathbf{S B}} \\
{[\mathbf{G P a}]}\end{array}$} & \multirow{2}{*}{$\begin{array}{c}\mathbf{E}_{\mathbf{C}, \mathrm{SAm}} \\
\mathbf{E}_{\mathrm{C}, \mathrm{SBm}} \\
{[\mathbf{G P a}]}\end{array}$} \\
\hline & 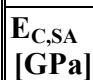 & $\begin{array}{r}\mathbf{E}_{\text {C,SAm }} \\
\text { [GPa] }\end{array}$ & $\begin{array}{c}\sigma_{\mathrm{E}} \\
{[\mathbf{G P a}]}\end{array}$ & $\begin{array}{l}\mathbf{E}_{\mathbf{C}, \mathbf{S B}} \\
\text { [GPa] }\end{array}$ & $\begin{array}{l}\mathbf{E}_{\mathrm{C}, \mathrm{SBm}} \\
\text { [GPa] }\end{array}$ & $\begin{array}{c}\sigma_{\mathrm{E}} \\
{[\mathrm{GPa}]}\end{array}$ & & & & \\
\hline \multirow{3}{*}{$\mathrm{NC} 1$} & 26.8 & \multirow{3}{*}{27.1} & \multirow{3}{*}{0.3} & 24.6 & \multirow{3}{*}{25.0} & \multirow{3}{*}{0.3} & 1.09 & \multirow{3}{*}{1.08} & 2.2 & \multirow{3}{*}{2.1} \\
\hline & 27.5 & & & 25.1 & & & 1.10 & & 2.4 & \\
\hline & 26.9 & & & 25.2 & & & 1.07 & & 1.7 & \\
\hline \multirow{3}{*}{$\mathrm{NC} 2$} & 32.2 & \multirow{3}{*}{32.2} & \multirow{3}{*}{0.7} & 30.3 & \multirow{3}{*}{30.1} & \multirow{3}{*}{0.7} & 1.06 & \multirow{3}{*}{1.07} & 1.9 & \multirow{3}{*}{2.1} \\
\hline & 31.4 & & & 29.2 & & & 1.08 & & 2.2 & \\
\hline & 33.0 & & & 30.8 & & & 1.07 & & 2.2 & \\
\hline \multirow{3}{*}{ LC1 } & 17.9 & \multirow{3}{*}{18.1} & \multirow{3}{*}{0.4} & 17.3 & \multirow{3}{*}{17.5} & \multirow{3}{*}{0.2} & 1.03 & \multirow{3}{*}{1.04} & 0.6 & \multirow{3}{*}{0.6} \\
\hline & 17.8 & & & 17.4 & & & 1.02 & & 0.4 & \\
\hline & 18.7 & & & 17.8 & & & 1.05 & & 0.9 & \\
\hline \multirow{3}{*}{ LC2 } & 22.8 & \multirow{3}{*}{22.6} & \multirow{3}{*}{0.3} & 21.8 & \multirow{3}{*}{21.6} & \multirow{3}{*}{0.2} & 1.05 & \multirow{3}{*}{1.05} & 1.0 & \multirow{3}{*}{1.0} \\
\hline & 22.8 & & & 21.6 & & & 1.06 & & 1.2 & \\
\hline & 22.2 & & & 21.4 & & & 1.04 & & 0.8 & \\
\hline
\end{tabular}

Analyzing the influence of the applied standard test method on a determination result of concrete modulus of elasticity it should be clearly stated that in the case of all tested specimens, independently from the type of used aggregate and cement matrix, Method A led to higher results than Method B. There are two probable reasons of such a phenomenon. Firstly, it may be the effect of strengthening and compaction of concrete structure during preloading cycles applied in Method A. Secondly, the higher value of the lower stress used in main loading cycles of Method A may be favourable for better concrete compression.

Nevertheless, the difference between values measured by Method A and B was more pronounced for normal-weight concretes than for lightweight ones. For both normal-weight series ( $\mathrm{NC} 1$ and $\mathrm{NC} 2$ ) Method A resulted in modulus higher by $2.1 \mathrm{GPa}$, (by ca $8 \%$ ) in relation to Method B, while for lightweight concretes LC1 and LC2 it gave values higher by $0.6 \mathrm{GPa}$ and $1.0 \mathrm{GPa}$ respectively (for both by ca $4 \%$ ). The smaller difference between moduli determined by both standard procedures for lightweight concretes probably results from more homogenous structure of these materials in comparison to normal-weight concretes. Generally, better structural homogeneity of lightweight concrete is caused by more regular shape and size of artificial particles, stronger bond between cement paste and porous aggregate and better compatibility of their stiffness, that means smaller difference of their moduli of elasticity. The direct prove of better homogeneity of lightweight concrete is its behaviour under compression up to failure, which leads to more linear stress-strain relation with a considerably reduced post-peak descending part in comparison to normal-weight concrete [15-17]. When concrete is loaded only up to one third of the ultimate stress, as it happens at modulus testing, it is harder to notice deviation from linearity of stress-strain relation. Nevertheless, charts of $\sigma-\varepsilon$ at cycled loading during modulus testing differ significantly for lightweight and normal-weight concretes. The examples of typical stressstrain behaviour of both types of concrete subject to modulus testing according to Methods $\mathrm{A}$ and $\mathrm{B}$ are presented in Figure 4. At the first main loading in Method A a certain curvilinearity of stress-strain relation is observed in the case of normal-weight concretes, while the relation for lightweight concretes is almost linear from the beginning. In Method $\mathrm{B}$, which followed Method A, these differences are not so visible because of earlier compression of concrete structure, mentioned above. Moreover, hysteresis loops, formed in sequent loading and unloading cycles, overlap more in the case of lightweight concretes than 
for normal-weight ones. As a result the strain stability of lightweight concretes was achieved already at the first loading in Method B and at the second loading in Method A, while for normal-weight concretes it was obtained at the second and the third loading respectively.

The shown differences between moduli determined in both standard methods should be considered as important, especially for normal-weight concretes. The values measured by Methods A and B for the same concrete differ more than moduli tested by the same method but for concretes differing by ca 2 strength classes. In the case of concrete made of stiffer aggregate, in comparison to sandstone applied in this research, the difference between moduli determined in both standard methods would probably be even higher. It cannot be ruled out that the application of a higher value of the lower stress in Method A, e.g. $\sigma_{b}=0.15 \cdot f_{c m}$ instead of $\sigma_{b}=0.1 \cdot f_{c m}$ used in this research, may also increase this difference.
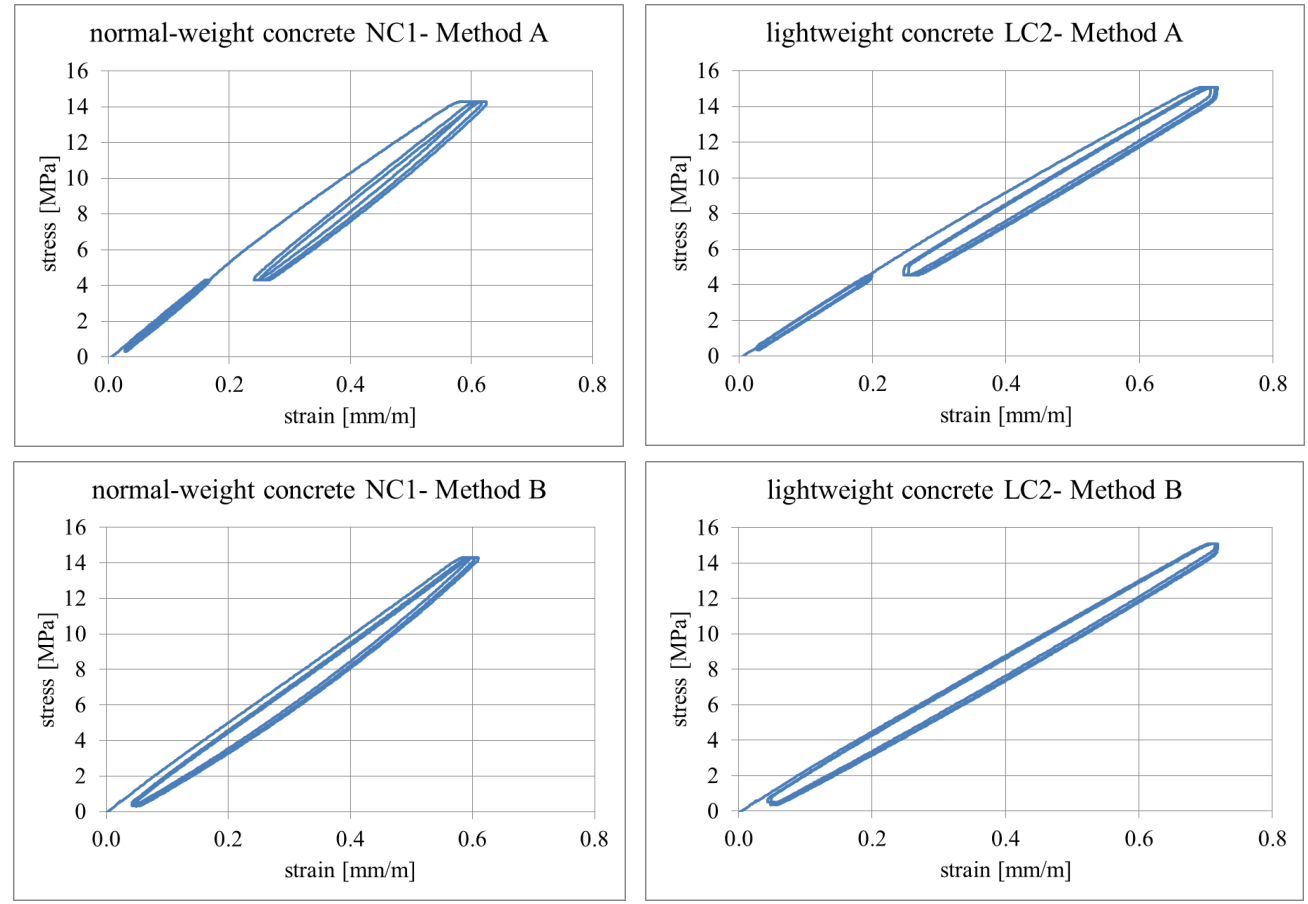

Fig. 4. Typical stress-strain relations at loading cycles of procedures A and B for normal-weight concrete (NC) and lightweight concrete (LC).

The measured values of modulus of elasticity differ significantly from those calculated according to designing standard Eurocode 2 (EN 1992-1-1[5]). The standard estimation for normal-weight concretes $\mathrm{NC} 1$ and $\mathrm{NC} 2$ gives the values of $23.8 \mathrm{GPa}$ and $26.3 \mathrm{GPa}$ respectively, while for lightweight concretes LC1 and LC2 corresponding moduli are 18.7 $\mathrm{GPa}$ and $22.7 \mathrm{GPa}$. It means that the values estimated for normal-weight concretes are lower even by $5.9 \mathrm{GPa}$ and $3.4 \mathrm{GPa}$ in relation to those determined by Method A and Method B respectively. However, in the case of lightweight concretes there is only a small difference between the values estimated and the specified according to Method A, while Method B leads to the measurements lower (by up to $1.2 \mathrm{GPa}$ ) than the estimated moduli.

\section{Conclusions}

The carried out tests and the analysis of the obtained results show that independently from type of used aggregate and cement matrix, two standard methods for determination of the 
secant modulus of elasticity lead to different measurements. The effect of strengthening and compaction of concrete structure during preloading cycles and a higher value of the lower stress used in the main loading cycles are probable reasons of the higher results achieved in tests performed according to Method A.

The difference between the values measured by Method A and B was more pronounced for normal-weight concretes than for lightweight ones. In the case of less homogenous concrete, e.g. made of stiffer aggregate than sandstone applied in this research, the difference would probably be even more significant. It cannot be ruled out that the application of a higher value of the lower stress in Method A, e.g. $\sigma_{b}=0.15 \cdot f_{c m}$ instead of $\sigma_{b}=0.1 \cdot f_{c m}$ used in this research, may also increase this difference. These two cases require to be proved in additional tests.

Although the new European Standard EN 12390-13 for determination of the secant modulus of elasticity sets a lot of problems related to testing procedures in order, the possibility of the application of two different standard methods, which give different test results, does not help researchers and structure designers. Perhaps one of these two standard methods should be indicated as the recommended one.

\section{References}

1. K. Mehta, P. Monteiro, Concrete microstructure, properties and materials (MCGraw Hill Education, 2013)

2. A. Nevile, Properties of concrete (Pearson, 2011)

3. L. Domagała, 5th Int. Conf. Concrete and concrete structures, 85 (2009)

4. L. Domagała, Materiały Budowlane (in Polish) 8, 55 (2017)

5. EN 1992-1-1 (2008)

6. DIN 1048-5 (1991)

7. Instrukcja ITB nr 194 (in Polish) (1998)

8. EN 12390-13 (2013)

9. B.D. Liu, W.J. Lv, P.F. Li, Constr. Build. Mater. 69, 133 (2014)

10. EN 12390-2 (2009)

11. EN 12390-3 (2009)

12. J. Newman, B.S. Choo, Advanced Concrete Technology (Elsevire, 2007)

13. EN 12390-7 (2009)

14. L. Domagała, Solid State Phenomena 258, 566 (2017)

15. M-H Zhang, O. Gjørv, ACI Mater. J. 88, 240 (1991)

16. H. Cui H, T. Lo, S. Memon, F. Xing, X. Shi, Constr. Build. Mater. 36, 845 (2012)

17. L. Domagała, J. Civ. Eng. Management 17, 36 (2011) 